\title{
Acute kidney Injury: Prevalence, Diagnosis, Causes and treatment
}

\author{
Article by Alermayehu Lelisa Duga \\ M.Sc clinical Research, Texila American University, Swaziland \\ Email:aduga@texilaconnect.com
}

\begin{abstract}
Introduction: Acute Kidney injury (AKI), is defined as an abrupt reduction in kidney function measured by a rapid decline in glomerular filtration rate resulting in the retention of metabolic waste products and dysregulation of fluid, electrolyte, and acid-base homeostasis. AKI is also defined in terms of a rise in serum creatinine concentration or by azotemia (a rise in blood urea nitrogen [BUN] concentration). The causes of acute renal disease can be related to the factors that interfere with structure and function of renal arteries, glomerular, renal tubules and urinary tracts. The current treatment for AKI is mainly supportive in nature; no therapeutic modalities to date have shown efficacy in treating the condition. Maintenance of volume homeostasis and correction of biochemical abnormalities remain the primary goals of treatment.

Methods: I undertook a systemic review different books and journals and came up with summary statement. Accordingly supporting evidence and general recommendation was generated for the future research.

Result: using the literature review the definition, causes and treatment algorithm of acute kidney injury was jotted down.

Conclusion: Acute kidney injury (formerly known as acute renal failure) is a syndrome characterised by the rapid loss of the kidney's excretory function and is typically diagnosed by the accumulation of end products of nitrogen metabolism (urea and creatinine) or decreased urine output, or both.
\end{abstract}

Keywords: Acute renal failure, creatinine, kidney, acute kidney injury, urea, blood urea nitrogen, dialysis.

\section{Introduction}

The kidneys are two organs located in the midsection on either side of spine in the middle of human back, just above the waist. They clean blood, keep the balance of salt and minerals in the blood, and help control blood pressure. When kidneys are damaged, waste products and fluid can build up in the body, causing swelling in ankles, vomiting, weakness, poor sleep, and shortness of breath(1). Acute Kidney injury (AKI), sometimes called acute renal failure (ARF), is defined as an abrupt reduction in kidney function measured by a rapid decline in glomerular filtration rate resulting in the retention of metabolic waste products and dysregulation of fluid, electrolyte, and acid-base homeostasis $(2,3)$.

AKI is usually defined in terms of a rise in serum creatinine concentration or by azotemia (a rise in blood urea nitrogen [BUN] concentration) (4). However, immediately after a kidney injury, BUN or creatinine levels may be normal, and the only sign of a kidney injury may be decreased urine production. A rise in the creatinine level can result from medications (eg, cimetidine, trimethoprim) that inhibit the kidney's tubular secretion, while a rise in the BUN level can also occur without renal injury, resulting instead from such sources as gastrointestinal (GI) or mucosal bleeding, steroid use, or protein loading. Therefore, a careful inventory must be taken before concluding that a kidney injury is present. Therefore, the definition of Acute Kidney injury remain subject to controversy, confusion and lack of consensus. (5). 
To address the lack of a universal definition for AKI a collaborative network of international experts representing nephrology and intensive care societies established the Acute Dialysis Quality Initiative (ADQI) and devised the RIFLE definition and staging system for AKI. Shortly after this many of the original members of the ADQI group collaborated to form the Acute Kidney Injury Network (AKIN) $(6,7)$. The AKIN group modified the RIFLE staging system to reflect the clinical significance of relatively small rises in serum creatinine. Most recently the international guideline group, Kidney Disease: Improving Global Outcomes (KDIGO) has brought together international experts from many different specialties to produce a definition and staging system that harmonises the previous definitions and staging systems proposed by both ADQI and AKIN. It is anticipated that this definition and staging system will be adopted globally. This will enable future comparisons of the incidence, outcomes and efficacy of therapeutic interventions for AKI (8).

\section{Pathophysiology of AKI}

Acute kidney injury (AKI) is associated with prolonged hospitalization, substantial health care resource consumption, high mortality, and can lead to progressive chronic kidney disease (CKD), including chronic kidney failure, in survivors(9). The causes of acute renal disease can be related to the renal anatomy most affected by the disorder as follows:

- Vascular - Blood from the renal arteries is delivered to the glomeruli.

- Glomeruli - Ultrafiltration occurs at the glomeruli forming an ultrafiltrate, which subsequently flows into the renal tubules.

- Renal tubule - Reabsorption and secretion of solute and/or water from the ultrafiltrate occurs within the tubules.

- Urinary tract - The final tubular fluid, the urine, leaves the kidney, draining sequentially into the renal pelvis, ureter, and bladder, from which it is excreted through the urethra.

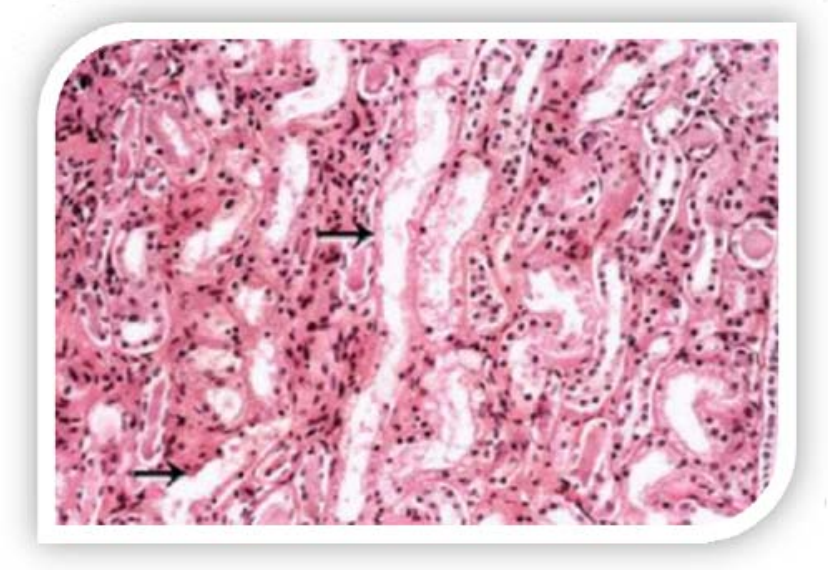

Fig. 1. Microscopic picture of a renal biopsy specimen shows renal medulla, which is composed mainly of renal tubules. Patchy or diffuse denudation of the renal tubular cells with loss of brush border is observed, suggesting acute tubular necrosis as the cause of acute renal failure(10).

\section{Classifications of AKI}

Any process that interferes with any of the structures and/or functions can cause renal disease. The causes of AKI can therefore be categorized as prerenal, renal, or postrenal(11) 


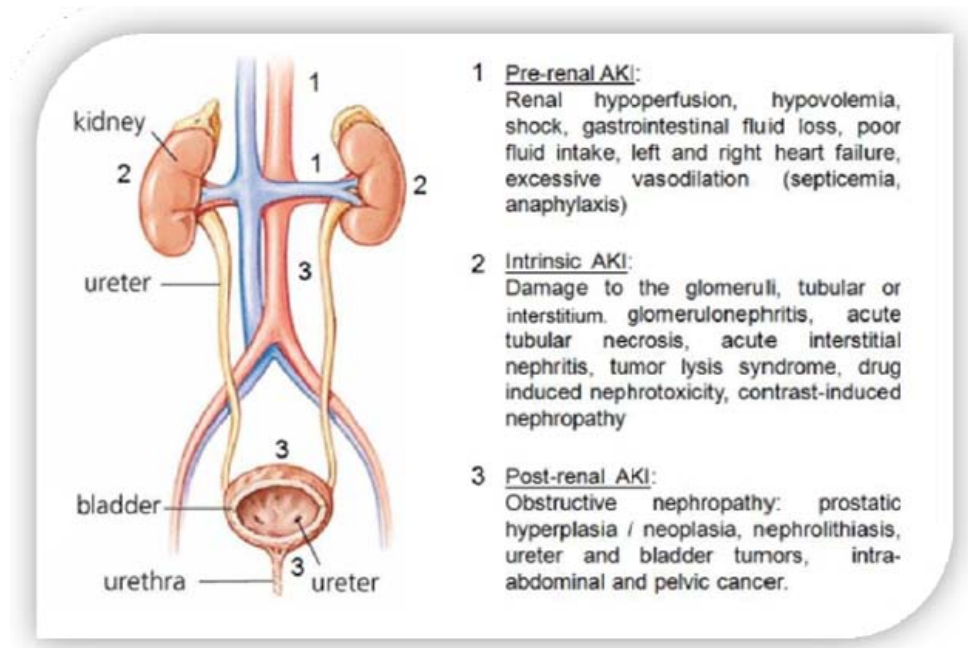

Fig.2 The brief Classifications of RKI

Table 2 classification and major causes of AKI

\section{A. Prerenal ARF}

I. Hypovolemia

A. Increased extracellular fluid losses: hemorrhage

B. Gastrointestinal fluid loss: vomiting, diarrhea, enterocutaneous fistula

C. Renal fluid loss: diuretics, osmotic diuresis, hypoadrenalism, nephrogenic diabetes insipidus

D. Extravascular sequestration: burns, pancreatitis, severe hypoalbuminemia (hypoproteinemia)

E. Decreased intake: dehydration, altered mental status

II. Altered renal hemodynamics resulting in hypoperfusion

A. Low cardiac output state: diseases of the myocardium, valves, and pericardium (including tamponade); pulmonary hypertension or massive pulmonary embolism leading to right and left heart failure; impaired venous return (e.g., abdominal compartment syndrome or positive pressure ventilation)

B. Systemic vasodilation: sepsis, antihypertensives, afterload reducers, anaphylaxis

C. Renal vasoconstriction: hypercalcemia, catecholamines, calcineurin inhibitors, amphotericin $\mathrm{B}$

D. Impairment of renal autoregulatory responses: cyclooxygenase inhibitors (e.g., nonsteroidal anti-inflammatory drugs), angiotensin-converting enzyme inhibitors, or angiotensin II receptor blockers

E. Hepatorenal syndrome

B. Intrinsic ARF

I. Renovascular obstruction (bilateral, or unilateral in the setting of one kidney)

A. Renal artery obstruction: atherosclerotic plaque, thrombosis, embolism, dissection aneurysm, large vessel vasculitis

B. Renal vein obstruction: thrombosis or compression

II. Diseases of the glomeruli or vasculature

A. Glomerulonephritis or vasculitis

B. Other: thrombotic microangiopathy, malignant hypertension, collagen vascular diseases (systemic lupus erythematosus, scleroderma), disseminated intravascular coagulation, preeclampsia

III. Acute tubular necrosis

A. Ischemia: causes are the same as for prerenal ARF, but generally the insult is more severe and/or more prolonged

B. Infection, with or without sepsis syndrome 
C. Toxins:

1. Exogenous: radiocontrast, calcineurin inhibitors, antibiotics (e.g., aminoglycosides), chemotherapy (e.g., cisplatin), antifungals (e.g., amphotericin B), ethylene glycol

2. Endogenous: rhabdomyolysis, hemolysis

IV. Interstitial nephritis

A. Allergic: antibiotics ( $\quad$-lactams, sulfonamides, quinolones, rifampin), nonsteroidal antiinflammatory drugs, diuretics, other drugs

B. Infection: pyelonephritis (if bilateral)

C. Infiltration: lymphoma, leukemia, sarcoidosis

D. Inflammatory, nonvascular: Sjögren's syndrome, tubulointerstitial nephritis with uveitis

V. Intratubular obstruction

A. Endogenous: myeloma proteins, uric acid (tumor lysis syndrome), systemic oxalalosis

B. Exogenous: acyclovir, gancyclovir, methotrexate, indinavir

C. Postrenal ARF (Obstruction)

I. Ureteric (bilateral, or unilateral in the case of one kidney): calculi, blood clots, sloughed papillae, cancer, external compression (e.g., retroperitoneal fibrosis)

II. Bladder neck: neurogenic bladder, prostatic hypertrophy, calculi, blood clots, cancer

III. Urethra: stricture or congenital valves

Intrinsic renal disorders - Intrinsic renal disease includes disorders that involve the renal vascular, glomerular, and/or tubular/interstitial pathology.

Vascular - Vascular causes of AKI include thrombosis (arterial and venous), hemolytic-uremic syndrome, malignant hypertension, and vasculitis.

Glomerular - The principal glomerular cause of AKI is acute glomerulonephritis, which is commonly postinfectious. AKI can be observed with most of the glomerulonephritides that can occur in childhood.

Tubular and interstitial disease - Acute tubular necrosis (ATN) results from ischemia due to decreased renal perfusion or injury from tubular nephrotoxins. All causes of prerenal azotemia can progress to ATN if renal perfusion is not restored and/or nephrotoxic insults are not withdrawn.

The administration of nephrotoxic agents, including aminoglycosides, amphotericin $\mathrm{B}$, and contrast agents, is a common cause of tubular disease. AKI can also be induced by the release of heme pigments, as with myoglobinuria due to rhabdomyolysis and hemoglobinuria due to intravascular hemolysis.

In children, acute interstitial nephritis most commonly results from a reaction to a drug that is thought to be hypersensitive in nature.

Postrenal - Postrenal AKI is due to bilateral urinary tract obstruction unless there is a solitary kidney. In neonates, urinary tract obstruction, due to posterior urethral valves is the most common cause of postrenal failure. Children with chronic obstructive uropathies are also at significant increased risk of AKI from ischemic and toxic insults(12).

\section{RIFLE classification system}

The Acute Dialysis Quality Initiative work group RIFLE (Risk of renal dysfunction, Injury to the kidney, Failure or Loss of kidney function) coined a definition and classification system for acute renal failure. 
Table 2 RIFLE classification system

\begin{tabular}{|c|c|c|c|}
\hline Stage & GFR Criteria & Urine Output Criteria & Probability \\
\hline Risk & $\begin{array}{l}\text { SCr increased } \times 1.5 \\
\text { Or } \\
\text { GFR decreased }>25 \%\end{array}$ & $\mathrm{UO}<0.5 \mathrm{~mL} / \mathrm{kg} / \mathrm{h} \times 6 \mathrm{~h}$ & \multirow[t]{3}{*}{$\begin{array}{l}\text { High sensitivity (Risk } \\
>\text { Injury >Failure) }\end{array}$} \\
\hline Injury & $\begin{array}{l}\text { SCreat increased } \times 2 \\
\text { or } \\
\text { GFR decreased }>50 \%\end{array}$ & $\mathrm{UO}<0.5 \mathrm{~mL} / \mathrm{kg} / \mathrm{h} \times 12 \mathrm{~h}$ & \\
\hline Failure & $\begin{array}{l}\text { SCreat increased } \times 3 \\
\text { or } \\
\text { GFR decreased } 75 \% \\
\text { or } \\
\text { SCreat } \geq 4 \mathrm{mg} / \mathrm{dL} \text {; acute } \\
\text { rise } \geq 0.5 \mathrm{mg} / \mathrm{dL}\end{array}$ & $\begin{array}{l}\mathrm{UO}<0.3 \mathrm{~mL} / \mathrm{kg} / \mathrm{h} \times 24 \mathrm{~h} \\
\text { (oliguria) } \\
\text { Or } \\
\text { anuria } \times 12 \mathrm{~h}\end{array}$ & \\
\hline Loss & \multicolumn{2}{|c|}{$\begin{array}{l}\text { Persistent acute renal failure: complete loss of kidney } \\
\text { function }>4 \mathrm{wk}\end{array}$} & \multirow[t]{2}{*}{ High specificity } \\
\hline ESKD* & \multicolumn{2}{|c|}{ Complete loss of kidney function $>3 \mathrm{mo}$} & \\
\hline
\end{tabular}

\section{Acute kidney injury network classification system}

The Acute Kidney Injury Network (AKIN) has developed specific criteria for the diagnosis of AKI. The AKIN defines AKI as abrupt (within 48 hours) reduction of kidney function, manifested by any 1 of the following (13). An absolute increase in serum creatinine of $0.3 \mathrm{mg} / \mathrm{dL}$ or greater $(\geq 26.4$ $\mu \mathrm{mol} / \mathrm{L})$

- A percentage increase in serum creatinine of $50 \%$ or greater (1.5-fold from baseline)

- A reduction in urine output, defined as less than $0.5 \mathrm{~mL} / \mathrm{kg} / \mathrm{h}$ for more than 6 hours

AKIN has proposed a staging system for AKI that is modified from RIFLE. In this system, either serum creatinine or urine output criteria can be used to determine stage according to the following Table.

Table 3 Acute Kidney Injury Network Classification/Staging System for AKI

\begin{tabular}{|l|l|l|}
\hline Stage & Serum Creatinine Criteria & Urine Output Criteria \\
\hline $\mathbf{1}$ & $\begin{array}{l}\text { Increase of } \geq 0.3 \mathrm{mg} / \mathrm{dL}(\geq 26.4 \mu \mathrm{mol} / \mathrm{L}) \text { or } \\
\text { 1.5- to } 2 \text {-fold increase from baseline }\end{array}$ & $<0.5 \mathrm{~mL} / \mathrm{kg} / \mathrm{h}$ for $>6 \mathrm{~h}$ \\
\hline $\mathbf{2}$ & $>2$-fold to 3-fold increase from baseline & $<0.5 \mathrm{~mL} / \mathrm{kg} / \mathrm{h}$ for $>12 \mathrm{~h}$ \\
\hline $3^{*}$ & $\begin{array}{l}>3 \text {-fold increase from baseline, or increase of } \\
\geq 4.0 \mathrm{mg} / \mathrm{dL}(\geq 35.4 \mu \mathrm{mol} / \mathrm{L}) \text { with an acute } \\
\text { increase of at least } 0.5 \mathrm{mg} / \mathrm{dL}(44 \mu \mathrm{mol} / \mathrm{L})\end{array}$ & $\begin{array}{l}<0.3 \mathrm{~mL} / \mathrm{kg} / \mathrm{h} \text { for } 24 \mathrm{~h} \text { or anuria } \\
\text { for } 12 \mathrm{~h}\end{array}$ \\
\hline
\end{tabular}

\section{Epidemiology of AKI}

Although the overall precise incidence and prevalence of AKI has been difficult to ascertain, a retrospective review from England estimated a yearly incidence for AKI in children as 0.8 per 100,000 populations (14). This incidence is about one-fifth of that found in adults. There are 
indications that the overall incidence of renal failure in children is rising with increased availability of advanced pediatric medical technology including bone marrow, hepatic, and cardiac transplantation, congenital heart disease surgery, and in the care of the very low birth weight infants (15). In a retrospective review of a tertiary center in the United States, one-third of hospitalized non-critically ill children developed AKI based on the modified pediatric RIFLE criteria (16). Risk factors for AKI included increasing length of hospital stay and costs, and exposure to nephrotoxic medications.

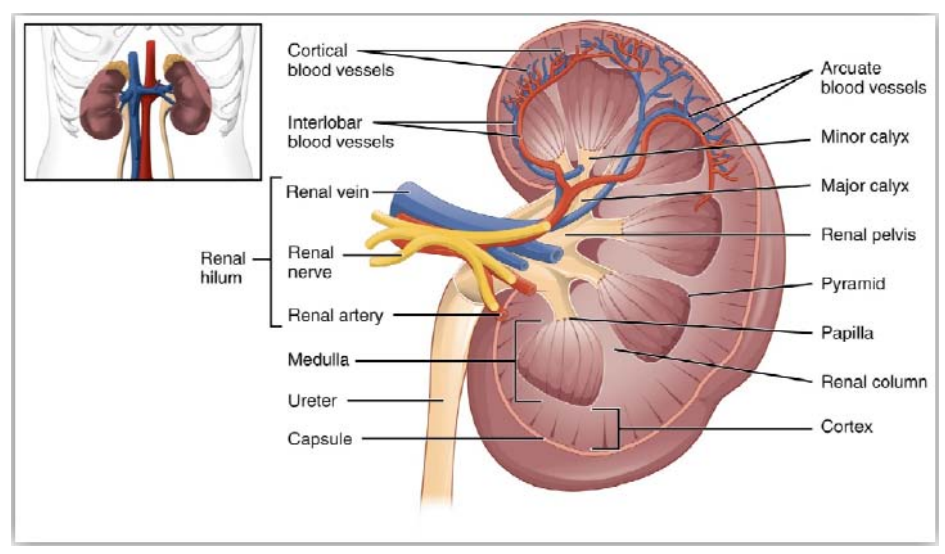

Figure 3 the image of kidney

Causes of AKI - As the prevalence of AKI has changed with the advances in medicine, so has the prevalence of different causes of AKI changed. This is especially true in tertiary care centers in developed countries where many children with pre-existing chronic diseases are at increased risk for AKI due to ischemia, drug toxicity, or infection (17).

This is illustrated in the following retrospective study of 248 patients cared for at a single tertiary referral center from 1998 to 2001 in the United States (18). Approximately two-thirds had an underlying comorbid condition.

- The most common causes of acute kidney injury (AKI) included ischemia (21 percent), nephrotoxic drugs (16 percent), sepsis (11 percent), and unknown (11 percent).

- Primary renal diseases accounted for only 7 percent of cases (17 cases) and included glomerulonephritis (9 cases), pyelonephritis (5 cases), and hemolytic uremic syndrome (3 cases).

- A quarter of the patients were neonates ( 0 to 30 days of age). In 27 percent of this group, AKI was caused by ischemia due to congenital cardiac disease.

In contrast, primary renal diseases are more likely to cause AKI in less developed countries (19).

This was best illustrated in a review of seven studies primarily from Asia (India [3 reports], New Zealand [1 trial], Singapore [1 trial]) that reported an incidence of primary renal disease (43 percent) causing ARF (ie, requiring dialysis therapy) in children. The following were the most common causes of ARF ranked in order of incidence:

- Acute tubular necrosis (ATN), (23 percent)

- Hemolytic uremic syndrome (HUS), (21 percent)

- Glomerulonephritis (13 percent)

- Intrinsic renal disease (9 percent), causes not specified

- $\quad$ Postoperative (7 percent)

- $\quad$ Sepsis (6 percent)

- Ischemia/prerenal (4.5 percent)

- Urinary tract obstruction (3 percent)

- Miscellaneous causes (13.8 percent) including metabolic disorders, renal venous thrombosis, hepatorenal syndrome, complication of organ transplantation 
Table 4 The Phases of AKI

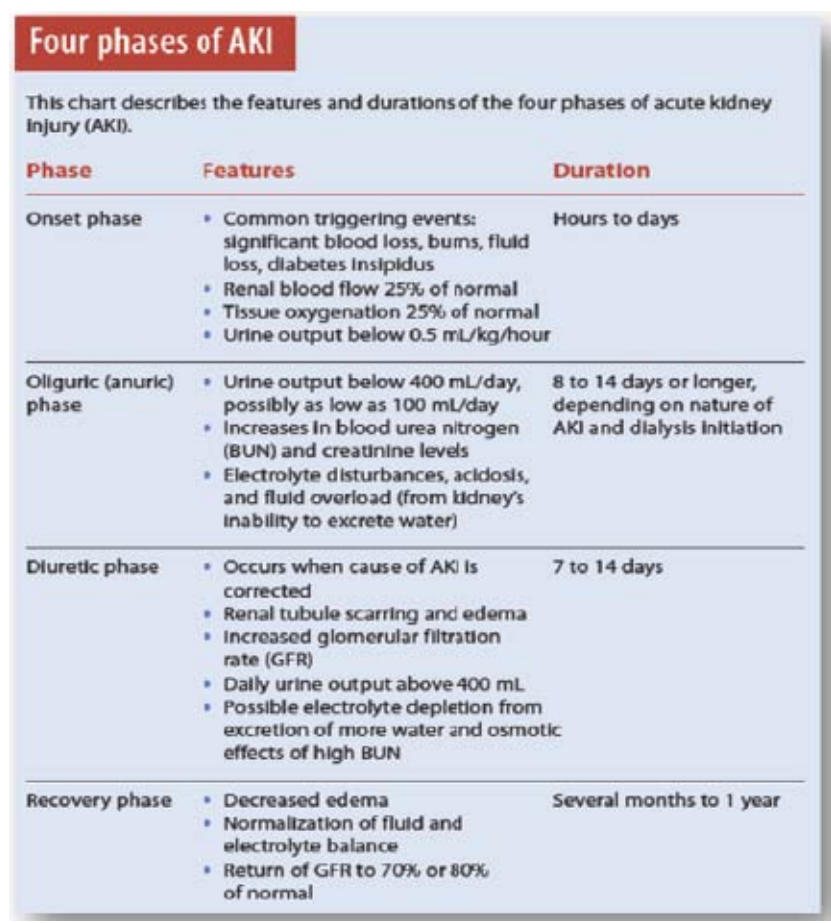

A case series of 311 children cared for at a single tertiary center in Thailand from 1982 to 2004 also demonstrated primary renal disease was more likely to cause AKI (20). In this report, the etiology of AKI included sepsis (21 percent), hypovolemia (12 percent), poststreptococcal glomerulonephritis (12 percent), systemic lupus erythematosus (10 percent), and other infectious diseases ( 9 percent).

In these studies, the most common cause of AKI in children was ATN due to either decreased renal perfusion (due to ischemia and sepsis) or nephrotoxic agents. In children, hypovolemia from excessive fluid losses from vomiting, diarrhea, burns, trauma is the usual cause of decreased renal perfusion (21).

\section{Clinical presentation}

A careful history and physical examination can frequently identify events and/or disease processes that underlie AKI and suggest an underlying diagnosis:

- A history of vomiting, diarrhea, hemorrhage, sepsis and/or decreased oral intake resulting in hypovolemia, associated with decreased urine output suggests AKI due to prerenal disease or ATN.

- Physical examination findings that include tachycardia, dry mucous membranes, sunken eyes, orthostatic blood pressure changes, and decreased skin turgor suggest hypovolemia, resulting in AKI due to prerenal disease or ATN.

- Bloody diarrhea with oliguria (defined as less than $500 \mathrm{~mL} / 1.73 \mathrm{~m} 2$ per day in children and less than $0.5 \mathrm{~mL} / \mathrm{kg}$ per hour in infants) or anuria (absent urine) is consistent with the hemolytic-uremic syndrome.

- A history of pharyngitis or impetigo, a few weeks prior to the onset of gross hematuria suggests post-infectious glomerulonephritis.

- Nephrotic syndrome, heart failure, and liver failure may result in edema and other signs of specific organ dysfunction.

- Hemoptysis in the presence of renal impairment suggests a diagnosis of pulmonary-renal syndrome, which includes Goodpasture's syndrome or granulomatosis with polyangiitis (formerly referred to as Wegener's granulomatosis) 
Texila International Journal of Clinical Research

Volume 3, Issue 2, Dec 2016

- Skin findings, such as purpura, malar rash, or petechiae, and/or joint pain favor a diagnosis of systemic vasculitis, such as systemic lupus erythematosus or Henoch Schönleinpurpura.

- Anuria or oliguria in a newborn suggests a major congenital malformation or genetic disease, such as posterior urethral valves, bilateral renal vein thrombosis, or autosomal recessive kidney disease.

- In the hospital, ATN resulting from hypotension (due to sepsis or intraoperative events) or from the administration of nephrotoxic medications (such as aminoglycosides or amphotericin-B) is the common cause of AKI (22).

Among patients who develop AKI in the hospital, the day of onset can be determined in the patient in whom the serum creatinine concentration is measured daily. Suppose, for example, that a child has had a stable serum creatinine concentration, which then begins to rise progressively on day five. In such a patient, there must have been some insult on day four or a cumulative insult that has become clinically apparent (most often aminoglycoside therapy). Careful perusal of the patient's chart may identify the precipitating event on day four (eg, hypotension, radiocontrast exposure).

\section{Evaluation and diagnosis}

In addition to a careful history and physical examination, the initial evaluation includes an estimation of the glomerular filtration rate, examination of the urine, and the use of other modalities.

Table 5 The metric Units used in evaluation and diagnosis of AKI

CONVERSION FACTORS OF METRIC UNITS TO SI UNITS

\begin{tabular}{lccc}
\hline Parameter & Metric units & Conversion factor & Sl units \\
\hline Amikacin (serum, plasma) & $\mu g / \mathrm{ml}$ & 1.708 & $\mu \mathrm{mol} /$ \\
Blood urea nitrogen & $\mathrm{mg} / \mathrm{dl}$ & 0.357 & $\mathrm{mmol} /$ \\
Calcium, ionized (serum) & $\mathrm{mg} / \mathrm{dl}$ & 0.25 & $\mathrm{mmol} / /$ \\
Creatinine (serum) & $\mathrm{mg} / \mathrm{dl}$ & 88.4 & $\mu \mathrm{mol} / /$ \\
Creatinine clearance & $\mathrm{m} / \mathrm{min}$ & 0.01667 & $\mathrm{~m} / \mathrm{s}$ \\
Gentamicin (serum) & $\mu \mathrm{g} / \mathrm{ml}$ & 2.09 & $\mu \mathrm{mol} /$ \\
Glucose & $\mathrm{mg} / \mathrm{dl}$ & 0.0555 & $\mathrm{mmol} / /$ \\
Lactate (plasma) & $\mathrm{mg} / \mathrm{dl}$ & 0.111 & $\mathrm{mmol} / 1$ \\
Tobramycin (serum, plasma) & $\mu g / \mathrm{ml}$ & 2.139 & $\mu \mathrm{mol} /$ \\
Urea (plasma) & $\mathrm{mg} / \mathrm{ml}$ & 0.167 & $\mathrm{mmol} / /$ \\
\hline
\end{tabular}

Note: Metric unit $\times$ conversion factor $=$ SI unit.

Serum creatinine concentration - Estimation of the glomerular filtration rate (GFR) gives an approximate number of functioning nephrons. Serum creatinine concentration is used clinically to estimate GFR. However, serum creatinine and estimation of GFR can only be used in patient with stable kidney function. With AKI, GFR is initially markedly reduced but there has not been time for creatinine to accumulate and for serum creatinine to accurately reflect the degree of renal function. In the setting of AKI, an elevated serum creatinine is usually observed but it has no diagnostic utility in the estimation of GFR. In addition, changes in serum creatinine can be used to clinically follow the course of disease. The normal range of serum creatinine concentrations varies by age in children as follows (23).

- Newborn - 0.3 to $1.0 \mathrm{mg} / \mathrm{dL}$ (27 to $88 \mathrm{micromol} / \mathrm{L}$ )

- Infant -0.2 to $0.5 \mathrm{mg} / \mathrm{dL}$ (18 to $35 \mathrm{micromol} / \mathrm{L})$

- Child - 0.3 to $0.7 \mathrm{mg} / \mathrm{dL}$ (27 to $62 \mathrm{micromol} / \mathrm{L}$ )

- Adolescent - 0.5 to $1.0 \mathrm{mg} / \mathrm{dL}$ (44 to $88 \mathrm{micromol} / \mathrm{L}$ )

Several formulas that utilize easily obtained values have been developed that help estimate the GFR in patients with chronic renal failure that have stable function and are discussed separately.

Urinalysis - The urinalysis is the most important noninvasive test in the diagnostic evaluation, since characteristic findings on microscopic examination of the urine sediment strongly suggest certain diagnoses (table $\underline{6}$ ). 
Table 6. Showing Correlation between urinary patterns and renal disease

\begin{tabular}{|l|l|}
\hline Urinary pattern & Renal disease \\
\hline $\begin{array}{l}\text { Hematuria with red cell } \\
\text { casts, dysmorphic red cells, } \\
\text { heavy proteinuria, or } \\
\text { lipiduria }\end{array}$ & Virtually diagnostic of glomerular disease or vasculitis \\
\hline $\begin{array}{l}\text { Multiple granular and } \\
\text { epithelial cell casts with } \\
\text { free epithelial cells }\end{array}$ & $\begin{array}{l}\text { Strongly suggestive of acute tubular necrosis in a patient with } \\
\text { acute renal failure }\end{array}$ \\
\hline $\begin{array}{l}\text { Pyuria with white cell and } \\
\text { granular or waxy casts and } \\
\text { no or mild proteinuria }\end{array}$ & $\begin{array}{l}\text { Suggestive of tubular or interstitial disease or urinary tract } \\
\text { Obstruction }\end{array}$ \\
\hline $\begin{array}{l}\text { Hematuria and pyuria with } \\
\text { no or variable casts } \\
\text { (excluding red cell casts) }\end{array}$ & $\begin{array}{l}\text { May be observed in acute interstitial nephritis, glomerular } \\
\text { disease, vasculitis, obstruction, and renal infarction }\end{array}$ \\
\hline Hematuria alone & Varies with the clinical setting \\
\hline Pyuria alone & $\begin{array}{l}\text { Usually infection; sterile pyuria suggests urinary tract } \\
\text { tuberculosis or tubulointerstitial disease }\end{array}$ \\
\hline $\begin{array}{l}\text { Few cells with little or no } \\
\text { casts or proteinuria } \\
\text { (normal or near-normal) }\end{array}$ & $\begin{array}{l}\text { In acute renal failure, prerenal disease, urinary tract } \\
\text { obstruction, hypercalcemia, myeloma kidney, some cases of } \\
\text { acute tubular necrosis, or a vascular disease with glomerular } \\
\text { ischemia but not infarction (scleroderma, atheroemboli); in } \\
\text { chronic renal failure, nephrosclerosis, urinary tract } \\
\text { obstruction, and tubulointerstitial disease }\end{array}$ \\
\hline
\end{tabular}

As examples:

- A normal or near-normal urinalysis, characterized by few cells with little or no casts or proteinuria, suggests prerenal disease, urinary tract obstruction, and some cases of acute tubular necrosis (ATN).

- Muddy brown granular casts and epithelial cell casts are highly suggestive of ATN. However, the absence of these urinary findings does not exclude the diagnosis.

- The finding of a red cell cast is diagnostic of glomerulonephritis, while the presence of proteinuria is generally indicative of some form of glomerular disease. The concurrent presence of hematuria with red cell casts, dysmorphic red cells, heavy proteinuria, or lipiduria can also help subclassify patients into those with an active "nephritic" sediment. This is commonly associated with AKI due to glomerulonephritis.

- Pyuria with white cell and granular or waxy casts and varying levels of proteinuria is suggestive of tubular or interstitial disease or urinary tract infection (see the picture below)

- White cells and white cell casts can also be seen in acute glomerulonephritis, particularly postinfectious glomerulonephritis. In this setting, however, there are also other signs of glomerular disease, such as hematuria, red cell casts, and proteinuria.

- Hematuria and pyuria with no or variable casts (excluding red cell casts) may be seen in acute interstitial nephritis, glomerular disease, vasculitis, obstruction, and renal infarction.

Urine sodium excretion - With AKI in children, measurement of the urine sodium concentration is helpful in distinguishing ATN from prerenal AKI due to effective volume depletion. The urine sodium concentration is usually above 30 to $40 \mathrm{mEq} / \mathrm{L}$ and below $10 \mathrm{mEq} / \mathrm{L}$ in the former and latter conditions, respectively. Since normal newborns have a relatively decreased ability to conserve sodium, prerenal disease is usually associated with somewhat increased urine sodium concentrations (less than 20 to $30 \mathrm{mEq} / \mathrm{L}$ ).

However, since the urinary sodium concentration is influenced by the urine output, there is substantial overlap between ATN and prerenal disease. As an example, a given rate of sodium 
excretion will be associated with a lower urine sodium concentration by dilution in patients who have a high urine output.

- A value below 1 percent suggests prerenal disease, where the reabsorption of almost all of the filtered sodium represents an appropriate response to decreased renal perfusion.

- A value between 1 and 2 percent may be seen with either disorder.

- A value above 2 percent usually indicates ATN.

- In newborns, prerenal disease and ATN are associated with FENa values of less than 2.5 percent and greater than 2.5 to 3.5 percent, respectively, because of their decreased ability to reabsorb sodium.

The FENa is most useful in patients with severe renal failure and low urine output (oliguria). It is less accurate in those with a normal or moderately reduced GFR because the value determining a prerenal state changes continuously with the GFR. FENa may also be elevated after the administration of either a distal or loop diuretic due to the increase in urine sodium excretion. Why this occurs is discussed in detail separately. A low FENa is not unique to prerenal disease, since it can occur in disorders associated with normal tubular function but a low GFR. These include acute glomerulonephritis, vasculitis, and acute urinary tract obstruction. It can also be seen when ATN is superimposed upon a chronic sodium-retaining state.

Urine osmolality - Loss of concentrating ability is an early and almost universal finding in ATN with the urine osmolality usually being below $350 \mathrm{mosmol} / \mathrm{kg}$. However, lower values similar to those in ATN may be seen in prerenal disease and are therefore of little diagnostic help. In contrast, a urine osmolality above $500 \mathrm{mosmol} / \mathrm{kg}$ is highly suggestive of prerenal disease.

Urine volume - The urine volume is typically, but not always, low (oliguria) in prerenal disease due to the combination of sodium and water avidity. In comparison, patients with ATN may be either oliguric or nonoliguric.

Response to volume repletion - Unless contraindicated, a child with a clinical history consistent with fluid loss (such as vomiting and diarrhea), a physical examination consistent with hypovolemia (hypotension and tachycardia), and/or oliguria should be administered intravenous fluid therapy. This fluid challenge attempts to identify prerenal failure that can progress to ATN if not treated promptly. However, such fluid infusion is contraindicated in those with obvious volume overload or heart failure.

Commonly used fluids are crystalloid solutions, such as normal saline $(20 \mathrm{~mL} / \mathrm{kg})$ administered over 20 to 30 minutes, which may be repeated. Restoration of adequate urine flow and improvement in renal function with fluid resuscitation is consistent with prerenal disease. However, if urine output does not increase and renal function fails to improve with the restoration of intravascular volume, invasive monitoring may be required to adequately assess the child's fluid status and help guide further therapy. 


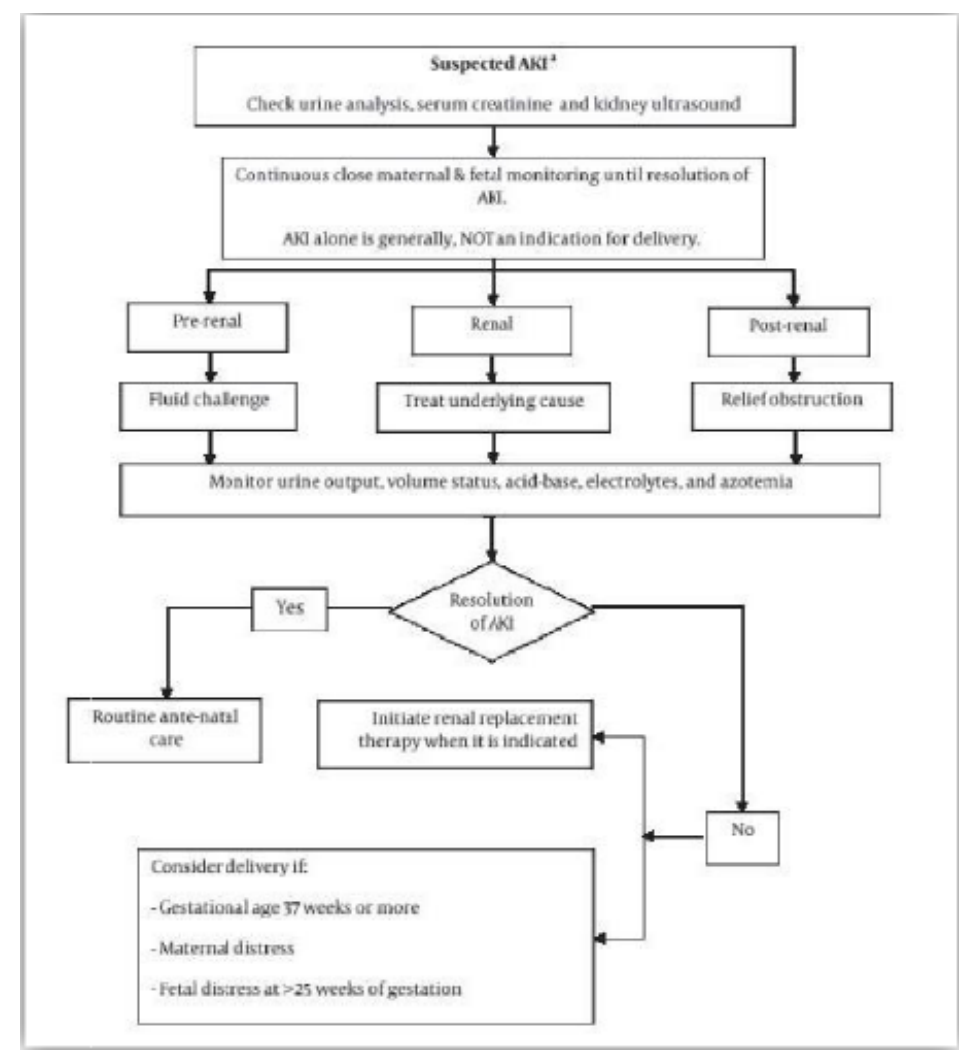

Fig 4; The diagnostic algorithm of AKI

\section{Additional laboratory measurements}

Complete blood count - Severe microangiopathic hemolytic anemia associated with thrombocytopenia in the setting of AKI confirms the diagnosis of HUS. . Severe hemolysis, whether drug-induced or secondary to hemoglobinopathies, may also result in ATN due to massive hemoglobinuria.

Other abnormalities - The measurement of additional blood components may be diagnostically helpful in certain settings. As examples:

- In children with a clinical picture consistent with rapidly progressive glomerulonephritis (RPGN), the presence of anti-neutrophil cytoplasmic antibodies (ANCA), anti-nuclear antibodies (ANA), anti-glomerular basement membrane (GBM) antibodies, antistreptococcal antibodies, and/or hypocomplementemia is associated with certain inflammatory disorders (24, 25).

- Eosinophilia and/or urine eosinophiluria may be present in some cases of interstitial nephritis.

- Markedly elevated uric acid levels may also induce AKI. Thus, tumor lysis syndrome secondary to chemotherapy treatment of childhood leukemia or lymphoma may result in AKI due to urate nephropathy (26).

- Although not diagnostically helpful, hyperkalemia, hyperphosphatemia, hypocalcemia, and acidosis can be observed in AKI:

- Hyperkalemia. The ability to maintain potassium excretion at near normal levels is generally maintained in patients with renal disease as long as both aldosterone secretion and distal flow are maintained. Thus, hyperkalemia generally develops in the patient who is oliguric or who has an additional problem, such as a high potassium diet and increased tissue breakdown.

- Hyperphosphatemia. Once the GFR falls below threshold levels, the renal excretion of phosphorus decreases, resulting in hyperphosphatemia. 
Texila International Journal of Clinical Research

Volume 3, Issue 2, Dec 2016

- Hypocalcemia. Hypocalcemia can result from hyperphosphatemia, decreased calcium absorption in the gastrointestinal tract (due to inadequate renal production 1, 25-vitamin D), and/or skeletal resistance to parathyroid hormone (PTH).

- Acid-base balance is normally maintained by the renal excretion of the daily acid load (about 1 $\mathrm{mEq} / \mathrm{kg}$ per day, derived mostly from the generation of sulfuric acid during the metabolism of sulfur-containing amino acids). Elimination of this acid load is achieved by the urinary excretion of hydrogen ions. A metabolic acidosis may therefore ensue with AKI.

Renal imaging - Renal ultrasonography should be performed in all children with AKI of unclear etiology. It can document the presence of one or two kidneys, delineate renal size, and help survey renal parenchyma (27). It is particularly useful in diagnosing urinary tract obstruction or occlusion of the major renal vessels.

Renal biopsy - A renal biopsy is most commonly obtained when noninvasive evaluation has been unable to establish the correct diagnosis (28).

Biomarkers - Biomarkers have been identified that may identify children in the beginning stages of AKI. In one study of 71 children and infants who underwent cardiopulmonary bypass surgery, urinary levels of neutrophil gelatinase-associated lipocalin (NGAL) were found to be elevated 2 hours after bypass in children who subsequently developed AKI. In addition to NGAL, interlukin-18 has been reported as an early marker of AKI in children (29, 30).

RIFLE Criteria - The Acute Dialysis Quality Initiative has developed criteria to standardize the reporting and classification of AKI in adults. Five levels of AKI are based upon degree of elevation of serum creatinine, urine output, and requirement for dialysis. In adults, the RIFLE criteria have been shown to predict mortality, renal outcome, and length and cost of hospital stay. Both prospective and retrospective studies have shown that renal injury occurs in a significant number of children admitted to the pediatric intensive care unit (PICU) when the RIFLE criteria are used to assess renal function (31). This was illustrated in a retrospective study of 3396 admissions to a single PICU between 2003 and 2006 (32). Six percent of patients $(n=194)$ had AKI on admission, and 10 percent of patients (n =339) developed AKI during their PICU stay based upon RIFLE criteria. Based on regression analysis, mortality increased as the severity of AKI increased based upon RIFLE score. Length of PICU stay was also increased in patients with AKI compared to those without AKI.

Standardized classification criteria, such as the RIFLE criteria, can be used as research tools to improve the understanding of AKI epidemiology and potentially identify treatable risk factors.

\section{Treatment of AKI}

Measures to correct underlying causes of acute kidney injury (AKI) should begin at the earliest indication of renal dysfunction. Serum creatinine does not rise to abnormal levels until a large proportion of the renal mass is damaged, because the relationship between the glomerular filtration rate (GFR) and the serum creatinine level is not linear, especially early in disease. Indeed, the rise of serum creatinine may not be evident before $50 \%$ of the GFR is lost.

It cannot be overstated that the current treatment for AKI is mainly supportive in nature; no therapeutic modalities to date have shown efficacy in treating the condition. Therapeutic agents (eg, dopamine, nesiritide, fenoldopam, mannitol) are not indicated in the management of AKI and may be harmful for the patient.

Maintenance of volume homeostasis and correction of biochemical abnormalities remain the primary goals of treatment and may include the following measures:

- Correction of fluid overload with furosemide

- Correction of severe acidosis with bicarbonate administration, which can be important as a bridge to dialysis

- Correction of hyperkalemia

- Correction of hematologic abnormalities (eg, anemia, uremic platelet dysfunction) with measures such as transfusions and administration of desmopressin or estrogens 


\section{Volume overload}

Furosemide can be used to correct volume overload when patients are still responsive; this often requires high intravenous (IV) doses. Furosemide plays no role in converting an oliguric AKI to a nonoliguric AKI or in increasing urine output when a patient is not hypervolemic. However, response to furosemide can be taken as a good prognostic sign.

\section{Hyperkalemia}

Hyperkalemia in patients with AKI can be life-threatening. Approaches to lowering serum potassium include the following:

- Decreasing the intake of potassium in diet or tube feeds

- Exchanging potassium across the gut lumen using potassium-binding resins

- Promoting intracellular shifts in potassium with insulin, dextrose solutions, and beta agonists

- Instituting dialysis

\section{Nephrotoxic agents}

In AKI, the kidneys are especially vulnerable to the toxic effects of various chemicals. All nephrotoxic agents (eg, radiocontrast agents, antibiotics with nephrotoxic potential, heavy metal preparations, cancer chemotherapeutic agents, nonsteroidal anti-inflammatory drugs [NSAIDs]) should be avoided or used with extreme caution. Similarly, all medications cleared by renal excretion should be avoided, or their doses should be adjusted appropriately.

A 2013 study indicated that triple therapy using nonsteroidal anti-inflammatory drugs (NSAIDs) with 2 antihypertensive medications - a diuretic along with an angiotensin-converting enzyme (ACE) inhibitor or an angiotensin-receptor blocker (ARB) — significantly increases the risk of hospitalization for AKI, particularly in the first 30 days of treatment with these drugs.

\section{Summary}

Acute kidney injury (formerly known as acute renal failure) is a syndrome characterised by the rapid loss of the kidney's excretory function and is typically diagnosed by the accumulation of end products of nitrogen metabolism (urea and creatinine) or decreased urine output, or both. It is the clinical manifestation of several disorders that affect the kidney acutely. Acute kidney injury is common in hospital patients and very common in critically ill patients. In these patients, it is most often secondary to extrarenal events. How such events cause acute kidney injury is controversial. No specific therapies have emerged that can attenuate acute kidney injury or expedite recovery; thus, treatment is supportive. New diagnostic techniques (eg, renal biomarkers) might help with early diagnosis. Patients are given renal replacement therapy if acute kidney injury is severe and biochemical or volume-related, or if uraemic-toxaemia-related complications are of concern. If patients survive their illness and do not have premorbid chronic kidney disease, they typically recover to dialysis independence. However, evidence suggests that patients who have had acute kidney injury are at increased risk of subsequent chronic kidney disease.

\section{References}

[1] Andreoli SP. Acute renal failure. CurrOpinPediatr 2002; 14:183.

[2] Akcan-Arikan A, Zappitelli M, Loftis LL, et al. Modified RIFLE criteria in critically ill children with acute kidney injury. Kidney Int 2007; 71:1028.

[3] Chan JC, Williams DM, Roth KS. Kidney failure in infants and children. Pediatr Rev 2002; 23:47.

[4] Chertow GM, Levy EM, Hammermeister KE, Grover F, Daley J:Independent association between acute renal failure and mortality following cardiac surgery. JAMA1998, 104:343-348).

[5] de Mendonca A, Vincent JL, Suter PM, Moreno R, Dearden NM, Antonelli M, Takala J, Sprung C, Cantraine F: Acute renal failure in the ICU: risk factors and outcome evaluation by SOFA score. Intensive Care Med2000, 26:915-921). 
Texila International Journal of Clinical Research

Volume 3, Issue 2, Dec 2016

[6] Flynn JT. Choice of dialysis modality for management of pediatric acute renal failure. PediatrNephrol 2002; 17:61.

[7] Hui-Stickle S, Brewer ED, Goldstein SL. Pediatric ARF epidemiology at a tertiary care center from 1999 to 2001. Am J Kidney Dis 2005; 45:96.

[8] Hui-Stickle S, Brewer ED, Goldstein SL. Pediatric ARF epidemiology at a tertiary care center from 1999 to 2001. Am J Kidney Dis 2005; 45:96.

[9] http://www.webmd.com/a-to-z-guides/understanding-kidney-disease-.basic-information

[10] Hiraoka M, Hori C, Tsuchida S, et al. Ultrasonographic findings of acute tubulointerstitial nephritis. Am J Nephrol 1996; 16:154.

[11] Hoschek JC, Dreyer P, Dahal S, Walker PD. Rapidly progressive renal failure in childhood. Am J Kidney Dis 2002; 40:1342.

[12] http://emedicine.medscape.com/article/243492-overview\#a1

[13] Harrison's Principles of Internal Medicine, 17th ed, Braunwald E, Fauci AS, Kasper DL, et al (Eds), McGraw Hill Book Company. New York 2008.

[14] Kist-van Holthe tot Echten JE, Goedvolk CA, Doornaar MB, et al. Acute renal insufficiency and renal replacement therapy after pediatric cardiopulmonary bypass surgery. PediatrCardiol 2001; 22:321.

[15] Kist-van Holthe tot Echten JE, Goedvolk CA, Doornaar MB, et al. Acute renal insufficiency and renal replacement therapy after pediatric cardiopulmonary bypass surgery. PediatrCardiol 2001; 22:321)

[16] Kidney Disease: Improving Global Outcomes. Clinical practice guideline on acute kidney injury. 2011. www.kdigo.org.

[17] (Kidney Disease: Improving Global Outcomes (KDIGO) Acute Kidney Injury Work Group. KDIGO Clinical Practice Guideline for Acute Kidney Injury. Kidney Int. 2012;2:124-138

[18]

[19] Lee WS, Ooi TL. Deaths following acute diarrhoeal diseases among hospitalised infants in Kuala Lumpur. Med J Malaysia 1999; 54:303.

[20] Lee WS, Ooi TL. Deaths following acute diarrhoeal diseases among hospitalised infants in Kuala Lumpur. Med J Malaysia 1999; 54:303.

[21] Mishra J, Dent C, Tarabishi R, et al. Neutrophil gelatinase-associated lipocalin (NGAL) as a biomarker for acute renal injury after cardiac surgery. Lancet 2005; 365:1231.

[22] Moffett BS, Goldstein SL. Acute kidney injury and increasing nephrotoxic-medication exposure in noncritically-ill children. Clin J Am SocNephrol 2011; 6:856.

[23] Mehta RL, Kellum JA, Shah SV, et al. 2007. Acute Kidney Injury Network (AKIN): report of an initiative to improve outcomes in acute kidney injury. Critical care, 11, R 31

[24] Molitoris BA, Levin A, Warnock D, et al. Improving outcomes of acute kidney injury: report of an initiative. Nat ClinPractNephrol 2007; 3 (8): 439-44

[25] Moghal NE, Brocklebank JT, Meadow SR. A review of acute renal failure in children: incidence, etiology and outcome. ClinNephrol 1998; 49:91

[26] Mehta RL, Kellum JA, Shah SV, Molitoris BA, Ronco C, Warnock DG, et al. Acute Kidney Injury Network: report of an initiative to improve outcomes in acute kidney injury. Crit Care. 2007. 11(2):R31

[27] Moghal NE, Brocklebank JT, Meadow SR. A review of acute renal failure in children: incidence, etiology and outcome. ClinNephrol 1998; 49:91.].

[28] Rossi R, Kleta R, Ehrich JH. Renal involvement in children with malignancies. PediatrNephrol 1999; 13:153.

[29] Schrier RW, Wang W, Poole B, Mitra A. Acute renal failure: definitions, diagnosis, pathogenesis, and therapy. J Clin Invest. 2004 Jul. 114(1):5-14.

[30] SVachvanichsanong P, Dissaneewate P, Lim A, McNeil E. Childhood acute renal failure: 22-year experience in a university hospital in southern Thailand. Pediatrics 2006; 118:e786

[31] Schneider J, Khemani R, Grushkin C, Bart R. Serum creatinine as stratified in the RIFLE score for acute kidney injury is associated with mortality and length of stay for children in the pediatric intensive care unit. Crit Care Med 2010; 38:933. 
Texila International Journal of Clinical Research

Volume 3, Issue 2, Dec 2016

[32] The Harriet Lane Handbook, 15th, Siberry GK, Iannone R (Eds), Mosby, St. Louis 2000)

[33] Washburn KK, Zappitelli M, Arikan AA, et al. Urinary interleukin-18 is an acute kidney injury biomarker in critically ill children. Nephrol Dial Transplant 2008; 23:566 